\title{
Estimating the Moderating Effect of Demographic Variables in B2B Ecommerce Adoption in Ghana
}

\author{
Otoo, Anthony Akai Acheampong, Zhiwen, Li, Antwi, Maxwell. Opuni \\ School of Management, Jiangsu University, 301 Xuefu Road, Zhenjiang, Jiangsu, P.R. China
}

\begin{abstract}
Different extraneous factors can intervene in the eventual acceptance and use of E-commerce platforms. Thus, an organisation may have a favourable technological space or environment which consists of compatible, complex and low cost software yet it may struggle to adopt technology due to other considerations. In the same way the organizational factors that includes top management support, HR IT competence and financial resources may be available yet it a firm may not simple adopt technology. The same can be said of having a favourable external environment which may consist of favourable competition, good trading partner pressure or favourable regulatory regime to adopt E-commerce. The reason is that each of these attributes may be enough to stimulate positive evaluation of E-commerce or online business value but the real adoption requires more than the factors in this case. Thus, certain stimulants have been discovered as playing intervening role between the desire or intention to adopt and the actual intention in both personal and corporate adoption of technology. In this paper, three extraneous stimulants or intervening mechanisms of B2B ecommerce adoption are analysed through structural equation analysis to examine their moderating effect. The results proves that size, facilitating conditions and the type of industry of a B2B ecommerce organisation can significantly influences its ecommerce adoption. Policy recommendations have been proposed in the subsequent sections of the analysis.
\end{abstract}

Keywords : Moderator, Size, Industry, facilitating conditions, SME, B2B

\section{INTRODUCTION}

In previous studies, it is established that adoption Ecommerce occurs only when an organisation appreciate its value. This is because E-commerce adoption and diffusion of technology demand a paradigm shift in the way an organisation thinks, acts and practices. This it requires a substantial reform of the entire organisation culture and citizenship behaviours of individuals, groups and process before it can be successful (Rose, et al, 2014). The first research objective of this study relates to the ability of technological factors to stimulate or hamper effective value for online business and its corresponding effect on E-commerce adoption among SMEs in Ghana. The results of this study support the claims in the extant literature that the state of technological development and appreciation within the country can affect firm's evaluation of the appropriateness of technology. Specifically in this study, the cost of technology, the complexity of technology and the compatibility of technology have been identified as key elements which can drive value for online business among firms. SMEs in this study affirmed the belief that when the cost of technology is very high, it will affect their interest due to their low level of resources available to them. Since SMEs in Ghana are less developed excessive sophistication may be a significant barrier to their adoption of E-commerce technology. 
The question regarding the environmental barriers to E-commerce adoption has also been answered in the findings of this research. The study outcome suggests that SMEs with top management support and dedication have a higher likelihood to stimulate positive E-commerce behaviour. This is because they have a better appreciation and tend to promote such an endeavour. In a similar way the value for online business for SMEs in Ghana is usually positive for firms that have IT inclined employees. The employees already have an appreciation of the value for technologies hence are ready to provide all the assistance and dedication needed to go through the challenges of technology adoption. For E-commerce adoption to be of substantial value the firm must have the financial resources needed to build and install a robust system which is reliable at all times. Unfortunately, most of the SMEs in developing countries such as Ghana do not have the requisite financial backbone to be able to achieve these objectives which affects their appreciation and value for online marketing platforms and its subsequent adoption.

The barriers and support systems for technology adoption that emanates from the external environment within which organisations operate have also been tested in this research. It is established from the statistical analysis of the research data that government policies, competitive intensity and rivalry and trading partner pressures are impetus for developing value for online business and E-commerce adoption. The global market has become excessively competitive and business organisations that earliest in time learns to leverage their advantages and positive outcomes of technology such as E-commerce adoption can attract effective and reliable trading partners, outperform competitors and gain the benefits of government incentives and intervening policies for SMEs E-commerce development which is fast becoming rampant in most developing economies in Sub-Saharan Africa where this research has taken place.

This paper explores the moderating influence of size of firm, facilitating conditions and industry of operations on the relationship between online business value and E-commerce adoption. It is postulated that these relationships are likely to be induced by the type of industry in which the organization is operating, the size of the firm and the presence of other facilitating conditions. In reality, it is not possible to study the influence of each of them in isolation yet there is the possibility of exploring the respective influence of each of the factors in composite structured equation function as conducted in the rest of the study. In the extant literature it is abundantly established that different extraneous factors can intervene in the eventual acceptance and use of E-commerce platforms. Thus, an organisation may have a favorable technological space or environment which consists of compatible, complex and low cost software yet it may struggle to adopt technology due to other considerations. In the same way the organizational factors that includes top management support, HR IT competence and financial resources may be available yet it a firm may not simple adopt technology.

The same can be said of having a favourable external environment which may consist of favourable competition, good trading partner pressure or favourable regulatory regime to adopt E-commerce. The reason is that each of these attributes may be enough to stimulate positive evaluation of $\mathrm{E}$ commerce or online business value but the real adoption requires more than the factors in this case. Thus, certain stimulants have been discovered as playing intervening role between the desire or intention to adopt and the actual intention in both personal and corporate adoption of technology. Three of these have been selected for extensive analysis due to their influence in the context of B2B business across the globe and these include the size of firm, 
industry of operations and facilitating conditions. The information following hypotheses was explored;

- H1: The size of a SME in Ghana moderates the relationship between the value it attaches to online business value and B2B E-commerce adoption

- H2: The industry of a SME in Ghana moderates the relationship between the value it attaches to online business value and B2B E-commerce adoption

- H3: The presence of facilitating conditions of a $S M E$ in Ghana moderates the relationship between the value it attaches to online business value and B2B E-commerce.

\section{LITERATURE SURVEY}

A large number of studies have narrowed the scope for studying the use of E-commerce by SMEs. According to Awiagah et al (2016), the adoption of Ecommerce by Small and Medium-Sized Enterprises is influenced by a variety of factors. In particular, Lim et al. (2016) noted that government support for the intention of SMEs to adopt E-commerce had a significant direct impact. Moreover, management support, the presence and reliability of national technology infrastructure and simulated pressures (advance imitation) can also stimulate E-commerce for SMEs. Lim et al (2016) present different perspectives to improve the understanding of SMEs Ecommerce adoption behaviour by combining the TOE framework and perceived strategic value. The study found that operational support and strategic decisionmaking had an impact on small and medium-sized enterprises and did not mitigate the impact on small businesses intention to move to online business (Lim et al., 2016). "Furthermore, perceived strategic value has a strong impact on medium-sized enterprises decision to choose an online platform but the impact on smaller size enterprises was largely small albeit significant.

In the work of Saffu et al. (2012), they point out that the adoption of E-commerce is significant in terms of perceived strategic value, and further contends that organizational support is the most powerful factor in perceived strategic value. From the perspective of DOI theory, Poorangi et al. (2013) examined the five factors of Rogers DOI theory (comparative advantage, compatibility, complexity, trialability and observability) and its intricate influence on the adoption of E-commerce by Malaysian SMEs across the manufacturing, service and agricultural sectors. The study found that there is an important positive relationship between management's level of confidence and the adoption of E-commerce. The trialability and observability factors affect management's level of confidence and the value they have for E-commerce which in turn affects the adoption of E-commerce. In the opinion of AbouShouk and Eraqi (2015) E-commerce adoption is more likely when management understands the perceived benefits of E-commerce and management's trust in the implementation of E-commerce. The compatibility of the E-commerce process with the existing corporate culture may affect employee resistance to the adoption of E-commerce, but there was no relationship between employee's resistance and adoption of E-commerce. In addition, the authors also found out that complexity has no significant relationship with the adoption of E-commerce.

Finally, the results also showed that comparative advantages generally increase the use of E-commerce by Malaysian SMEs. However, the study did not further investigate different aspects of comparative advantage. The work of Poorangi et al. (2013) is completed by another study on E-commerce adoption by Poorangi et al. (2013) can be complemented by Ndaizigaye and MacArthur (2014) and Soleimani (2012). According to Ndayizigamie and McArthur (2014) comparative advantages improves access to 
information, expand the market, reduce the cost of maintaining up-to-date company information which enables owners and managers to greatly drive Ecommerce adoption by SMEs. Suleimani et al. (2012) presents similar opinion but adds advocates that compatibility helps organisations to reduce internet service costs, which encourages companies to adopt E-commerce. Ahmad et al., (2015) supports this assertion by maintaining that the compatibility of Ecommerce with the company's preferred work practices and company values simplifies E-commerce implementation process for small and medium-sized enterprises. Based on the TOE framework, Chen et al. (2014) lists the environmental structure (competitors, governments, industries, suppliers and customers) as the most important consideration for SMEs in the decision to adopt E-commerce. For example Saffu et al. (2012) found out that SMEs in South-East Asia have the least technical structure. Saffu et al. (2012) further contends that perceived useful, ease of use, organization preparedness and external pressure are major stimulators to E-commerce adoption. The external pressure of trading partners is elaborated by Kurnia et al., (2015) while external pressure from competitors is also evaluated in the work of Lim et al., (2016).

Other external drivers of E-commerce adoption dominant in the extant literature includes external consultants and E-commerce solution providers (Ahmad et al., 2015), Government (Ahmad et al., 2015; Lim et al., 2016a) can influence the adoption of E-commerce. While many studies have shown the importance of the environmental factors in stimulating E-commerce adoption among SMEs, Sin et al. (2015) conclude that there is no relationship between the environmental context and the adoption of E-commerce by SMEs in the North Malaysia, because of its relatively conservative culture. Within the TOE framework, it must also be emphasized that influential internal stakeholders, such as business owners, managers, and employees, have proven to be able to lead E-commerce adoption decisions through a variety of research. Therefore, factors such as the support of business owners or managers (Allawi and Ali, 2015; Govan Dallaju et al., 2014;) and employee information technology (IT) skills (Govin Daraju et al., 2014) can significantly contribute to the adoption of E-commerce by Small and Medium Enterprises. However, skilled workforce does not appear to be conclusive, as Ndayizimi and MacArthur (2014) and Alrawabdeh (2016) fail to see the significant relationship between this factor and the adoption of E-commerce by SMEs. In addition, strong and active E-commerce adoption and employees of IT skills, domestic and national information and communication technology (ICT) infrastructure, national internet rates, etc have been proven (Hadili et al, 2014).

On the other hand, an inconclusive relationship between E-commerce adoption and organizational preparation is seen in the work of Kurnia et al (2015). This is because while organizational resources and governance structures which are constructs of organizational readiness is statistically significant and has a positive relationship with the adoption of $\mathrm{E}$ commerce however, perceived benefit, which is also a construct of organizational readiness is not supported empirically as having a beneficial impact on the adoption of E-commerce in SMEs in Malaysia. These contradictory results suggest that the impact of the specific structure of the organization's preparation may vary. It is also important to recognize the role of culture in identifying the adoption of E-commerce drivers by SMEs. Different organizational cultures can also lead to different levels of maturity in Ecommerce adoption. Among other types of cultures (e.g. market culture, hierarchical culture and clan culture), Senarathna et al. (2014) assert that an, aristocratic culture would be support SMEs to adopt E-commerce among. The characteristics of market culture and hierarchical culture indicate that, despite government efforts to promote the use of technology, 
the rate of technology adoption of SMEs remains low, but there is a negative correlation in the adoption of E-commerce. As a result, some researchers have chosen to investigate factors that influence entrepreneurs' decisions by measuring technology readiness (TR) in particular. For example, Astuti and Nasution (2014) show that TR in SMEs in Indonesia has moderate differences, with significant differences in the background of TR among the different respondents. The results of the survey therefore mean that SMEs are further supporting the adoption of $\mathrm{E}$ commerce.

\section{RESEARCH METHODOLOGY}

\section{Research Design and Research Models}

This section of the study applied the original data that had been collected in the three previous sections since it is part of integrated studies. The only difference was in the management of the data. While individual variables in each of the three constructs (technology, organisation and environment) were analyzed in the earlier chapters, the composite values were rather analysed and related to online business value and E-commerce adoption. In the first place, three components of technology (cost of technology, complexity of technology and compatibility of technology) were statistically composed into one constructs after which the three variables in organisation (top management support, HR IT competence and financial resources) were also composed into one construct. Finally, the three components of environment namely competitive intensity, regulatory environment and trading partner pressure were also composed into one single construct. In order to measure size, the composite value of three questions in the questionnaire was used while 10 items in the questionnaire were composed to measure facilitating conditions. The industry used non-scalable dummy variables which were recorded as part of the first section of the questionnaire in which the respondents indicated their industry of operations. This approach was feasible since the denominating scale for collecting data about each variable was the five point likert scale. For this reason problems of differences in the unit of measurement were avoided. As in previous chapters, the composite reliability test, Cronbach alpha correlation coefficient tests were used to check how each constructs is internally consistent or how each variable fits well into the designated constructs. The WARP PLS software was further used to conduct analysis of the moderating relationship among the variables.

\section{Structural Equation Analysis}

This study employs a novel mixed structural equation model to establish causes and effect relationship between the dependent and independent variables as used in Bediako et al (2018). According to Saunders et al (2008) a structural equation model produces robust inferences relative to the traditional regression model. Structural equation is preferred in this study as it allows the analysis of influence of predictor variables on different dependent variables simultaneously. Moreover, structural equations are flexible and help to specify the substantive interest of the model, allow growth curve models to be merged in order to isolate unique patterns. The specific model used in our study is expressed in a matrix form as follows:

$$
\begin{gathered}
{\left[\begin{array}{l}
y_{1} \\
y_{2} \\
\Lambda \\
y_{p}
\end{array}\right]=\left[\begin{array}{cccc}
0 & \beta_{12} & \Lambda & \beta_{1 p} \\
\beta_{21} & 0 & \Lambda & \beta_{2 p} \\
\Lambda & \Lambda & \Lambda & \Lambda \\
\beta_{p 1} & \beta_{p 2} & \Lambda & 0
\end{array}\right]\left[\begin{array}{l}
y_{1} \\
y_{2} \\
\Lambda \\
y_{p}
\end{array}\right]+\left[\begin{array}{cccc}
\gamma_{11} & \gamma_{12} & \Lambda & \gamma_{1 q} \\
\gamma_{21} & \gamma_{22} & \Lambda & \gamma_{2 q} \\
\Lambda & \Lambda & \Lambda & \Lambda \\
\gamma_{p 1} & \gamma_{p 2} & \Lambda & \gamma_{p q}
\end{array}\right]\left[\begin{array}{c}
x_{1} \\
x_{2} \\
\Lambda \\
x_{q}
\end{array}\right]+\left[\begin{array}{l}
\zeta_{1} \\
\zeta_{2} \\
\Lambda \\
\zeta_{p}
\end{array}\right]} \\
\mathbf{y}=\mathbf{B y}+\boldsymbol{\Gamma x}+\boldsymbol{\zeta} .
\end{gathered}
$$

where for each of the causal parameters, the $\gamma$ 's and the $\beta$ 's, the subscripts follow the same pattern. In the matrix, the $\mathrm{p}$ by $\mathrm{p}$ B matrix holds the coefficient of regression of the $y$ variables whereas the other $y$ variable with 0 's on the diagonal indicates that a variable cannot cause itself. The model also contains 
the $\mathrm{p}$ by $\mathrm{q}$ Гmatrix which contains the coefficients of the y's on the x's. The error vector (errors-inequations or specification errors) $\zeta$, is $\mathrm{p}$ by 1 . For example we assumed that $\mathrm{E}(\mathrm{y})=0$ and $\mathrm{E}(\mathrm{x})=0$ and these have absolutely no impact on both the variance and the covariances of the variables if we assume the independence of $\mathrm{x}$ and $\zeta$.

\section{RESULTS}

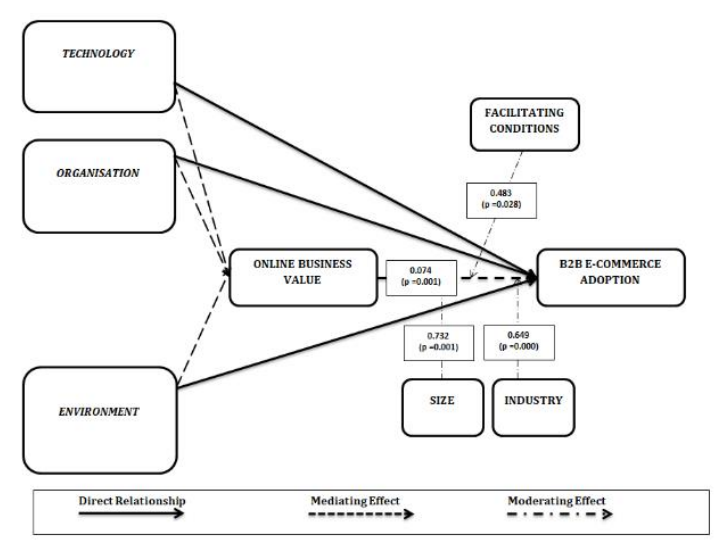

Figure 1: Path Analysis of Moderating Effect of Size, Industry and Facilitating Conditions

\begin{tabular}{lllll}
\hline Paths & Hypothesis & $\begin{array}{c}\text { Path } \\
\text { Coefficient }\end{array}$ & P Values & Status \\
\hline eValue $\rightarrow$ eCom & (Est) & 0.074 & 0.001 & Accepted \\
eValue $\rightarrow$ Size $\rightarrow$ e-Com & H4a & 0.732 & 0.001 & Accepted \\
eValue $\rightarrow$ IND $\rightarrow$ e-Com & H4b & 0.649 & 0.000 & Accepted \\
eValue $\rightarrow$ FC $\rightarrow$ e-Com & H4c & 0.483 & 0.028 & Accepted \\
\hline
\end{tabular}

Two tests of moderating relationship has been conducted to establish the validity of the effect of size, industry and facilitating conditions on the relationship between online business value and ecommerce adoption. The first test in figure 12 as summarized in table 33, uses the structural equation analysis model and the results show that the moderating effect of the size of a firm on the relationship between online business and B2B Ecommerce adoption is positive. This is evident in the path coefficient value of 0.732 and a significant value of 0.001 . The study further confirms the validity of the claim that the industry of operation moderates the relationship between online business value and $\mathrm{E}$ commerce adoption. This means that while business organizations may have a stronger sense of appreciation for online business, the type of industry they operate can influence the decision to adopt Ecommerce or not. This is because some industries are much easier to transition to E-commerce than other type of industries. The acceptance of this hypothesis is supported by the path coefficient value is 0.649 and the significant value is 0.000 which is less than 0.05 . Finally, the hypothesis that facilitating conditions moderates the relationship between online business value and ecommerce adoption is also accepted based on the path coefficient value of 0.483 which is statistically significant at $95 \%$ confidence interval ( $p$ value $=0.028)$.

\section{CONCLUSIONS AND RECOMMENDATION}

In this research, the moderating effect of three factors has been examined and these are the size of the firm, the industry of operation and the facilitating conditions. Each of them returned a positive and statistically significant influence on the relationship between online business value and E-commerce adoption. The results show that where facilitating conditions abound, they potentially increase the propensity to adopt E-commerce by improving awareness and value of online business intentions of SMEs. This is consistent with the earlier work of Lamie, et al (2011) that claims that facilitating conditions enrich online business initiatives. Further, the findings are also consistent with other past literature on E-commerce adoption shows that facilitating condition has a significant impact on behavioural intentions (Saini, et al, 2017).

Kim, and Lee (2009) found out that facilitating conditions positively moderated the relationship between technology readiness and the adoption of mobile banking while $\mathrm{Lu}$ at (2010) EscobarRodriguez and Carvajal-Trujillo (2013) found out that online buying intentions of airline consumers were moderated by facilitating conditions based on the TAM model. In the same way the size of the firm 
were also found to positively moderate the relationship between online shopping value and Ecommerce adoption. These findings are consistent with the claim of Sobihah and Lukman, (2015) that the adoption of B2B E-commerce is influenced by comparative advantage, top management support, government support and enterprise size. Similarly, the work gives credence to the earlier works of Sila (2013) that SMEs may not have access to the same infrastructure as large companies, so the impact of Ecommerce may vary depending on the size of the company.

The moderating influence of industry is a major observation in this study as the findings are also consistent with previous studies. For example, Shemi (2014) found that the main obstacles to the adoption of E-commerce were the slow speed of the Internet, poor telecommunications, lack of industry support and the lack of E-commerce policies in the country. Different industries provide stimulus packages and different degree of leveraging technology and external constrains for E-commerce adoption. In industries where this is visible there is a higher likelihood for SMEs to be motivated to adopt technology in the most accurate way than where there is none.

\section{Recommendations}

It is without doubt that SMEs E-commerce adoption is an essential ingredient in the economic development of every country. With rising cost of transport and other logistics across countries, Ecommerce has become an indelible aspect of modern business and the need for SMEs to take advantage of them is eminent. Thus, the following suggestions have been made in order to improve the value or appreciation of SMEs in online shopping for subsequent adoption

Developers of the E-commerce platforms must be mindful of the needs of the SMEs and their resource capabilities. There is the need to explore cheaper E- commerce platforms and develop them to suit SMEs that are unable to find the open source systems suitable for their specific operations

SMEs in general must develop the capacity to change and explore the emerging field of E-commerce. While external forces can provide the platform for SMEs to mature and grow their business, the ultimate decision and initiative depends on the SMEs themselves. This is where it is important for the top managers in SMEs to develop critical interest and value for E-commerce technology which can then be passed on to their employees to begins a chain of innovation diffusion reform.

Government support for SMEs to develop capacity for E-commerce integration is still a key element in the African and the Ghanaian market. It is recommended that SMEs in Ghana constitute associations or unions through which they can press home their specific IT needs which can support their eventual adoption of E-commerce platforms. One of the reference studies in this research is the earlier work of Lim et al (2016) which found that operational support and strategic decision-making had an impact on small and medium-sized enterprises and did not mitigate the impact on small businesses intention to move to online business (Lim et al., 2016). It was further the contention of these researchers that perceived strategic value has a strong impact on medium-sized enterprises decision to choose an online platform but the impact on smaller size enterprises was largely small albeit significant. This study provided one of the important precursors to exploring the influence of organisation size in the interplay between online business value and ecommerce adoption by SMEs.

However, the results of this study does not appear to support this claim as the findings suggest that a larger organisation has a higher likelihood of attaining Ecommerce adoption better and faster than smaller ones. Further in this regard the analysis support the earlier claims in the literature that industrial differences can speed up the rate of ecommerce 
adoption among B2B firms. In some industries as was revealed in the literature, the percolation of ecommerce is relatively slowed down by several confounding factors namely political, economic, socio-cultural, technological, environmental and legal factors some of which are beyond the control of small scale enterprises. In such situations it requires a collective effort of the group of smaller enterprises or state to break through barriers such as the development of a regulatory framework for ecommerce practices and security, cross border transactional regulations between states or countries etc. Venkatesh et al (2003) in their UTAUT model suggested the presence of facilitating conditions as a major factor in driving technology adoption.

While Venkatesh et al (2003) explored technology in general; the specific implications of their work on the adoption of ecommerce technology among SMEs in Ghana have been validated in this study. There is ample evidence that when organisations have favorable and supporting work environment, they easily afoot and incorporate technology into their daily business operations as a results of the value they gain from the perceived ease of use and perceived usefulness of the ecommerce technology.

\section{Future Research}

Future research is needed to explain a number of tangential issues that came up during the research. For example new research direction should consider other constructs that are not explored by the TOE model. For example the role of national cultural dimensions in technology adoption at the organizational level must be explored. This area of study was first proposed Hoftsede (2005) but it is yet to benefit from extended studies in Africa. Moreover, more complex analytical techniques such as systems dynamics model must be explored in advanced studies. Another important issue with online shopping is the greater sense of insecurity that characterize the online business platform which affect consumer trust in several ways. Previous studies have asserted that cybercrime in the midst of insufficient regulatory framework remains a major challenge to the advancement of modern online shopping hence the need for interconnected regulatory framework to overcome these challenges. The situation is even more serious in cross border transactions where trading laws differ from country to country. Eventhough the European Union has tried setting the pace to offer insight and guidance in legal basis for online transaction within the union, it has not achieved the desired results hence the occasional challenges with customers and sellers on online platforms across the European Union. Today online copyright breaches appear to be the most important legal challenges confronting several well established brands due to the opaqueness of these online enterprises and the effect on companies or SME are very monumental. It is even more difficult for SMEs within developing country milieu that is already saddled with several challenges and operational difficulties in weak financial markets systems in Africa.

Within the context of enhancing SMEs viability through ecommerce adoption, it is highly recommended that future research must focus on exploring the integrated cross national regulatory framework to protect online transactions across countries. Even as these laws appear to be taking sometime to bud, future research must also aim at looking for appropriate mechanisms and techniques that SMEs in developing countries such as Ghana can adopt to enhance online market surveillance to overcome the challenges of cybercrime and internet fraud which has emptied the coffers of several of these SMEs in the past. Finally, future research is also needed on the strategies needed to gain high visibility in online market or ecommerce market. It is the contention of Ocloo (2019) that in most developing countries, the target is to ensure that as many companies as possible adopt ecommerce platforms and develop mechanism and measures to overcome the 
competition at home. However the history of industries is littered with several failed enterprises that did not carefully evaluate the competitive urge in adopting online platform before embarking on this adventure. It is very true that while online platforms may be helpful and while technological, organizational and environmental factors may play a role in the success of an organization, the internet may not be a good option for every enterprise to simply spray themselves on the internet, in search of customers. There are other things that must be put in place in order to achieve these objectives and high visibility hence and the need to explore in future research studies at the developing countries level.

\section{Limitations}

This study has some limitations in terms of the number of participants. A total of 200 SMEs took part in the study. Thus if more people had taken part in the study the results would have probably turned out differently. Moreover, the sample was selected at random meaning that other opinion were not considered in this study. Another limitation of the study is the respondent's attitude to the questions. They were not mandated to be truthful even though they were encouraged to be as frank as possible. In any of these instances, the responses could have been compromised and this affects the validity of the findings of this study.

\section{CONFLICT OF INTEREST}

The authors of this research ardently state that there was no conflict of interest in the study.

\section{REFERENCES}

[1]. Abdul-Hamid, I. K., Shaikh, A. A., Boateng, H., \& Hinson, R. E. (2019). Customers' Perceived Risk and Trust in Using Mobile Money Services-an Empirical Study of Ghana.
International Journal of Online

business Research (IJEBR), 15(1), 1-19.

[2]. Abou-Shouk, M., Lim, W. M. and Megicks, P. (2013). E-commerce and small tourism businesses in developing countries, Drivers versus boundaries of adoption. Tourism Planning \& Development, 10(3): 249-66.

[3]. Ahluwalia, P., \& Merhi, M. I. (2020). Understanding Country Level Adoption of Ecommerce: A Theoretical Model Including Technological, Institutional, and Cultural Factors. Journal of Global Information Management (JGIM), 28(1), 1-22.

[4]. Alegbeleye, G. O., \& Ige, N. A. (2020). Evaluating the use of information systems among employees in food and beverage companies in Lagos, Nigeria. Library Philosophy and Practice, 1-10.

[5]. Attuquayefio, S. (2019). Development of a Conceptual Framework to Support ICT Adoption by Ghanaian Higher Education Students. International Journal of Education \& Development using Information \& Communication Technology, 15(4).

[6]. Cui, Y., Mou, J., Cohen, J., Liu, Y., \& Kurcz, K. (2020). Understanding consumer intentions toward cross-border m-commerce usage: A psychological distance and commitment-trust perspective. Electronic Commerce Research and Applications, 39, 100920.

[7]. Daferighe, E. E. (2019). Adoption Of CuttingEdge Information Technology And Development Of SMEs In Nigeria. Archives of Business Research, 7(5).

[8]. Faloye, D. O. (2014). The adoption of Ecommerce in small businesses, An empirical evidence from retail sector in Nigeria. Journal of Business and Retail Management Research, 8(2): 54-64.

[9]. Fetu, A. (2019). Opportunity and Challenges of Electronic-Banking System in Commercial Bank 
of Ethiopia (A Case Study on Gurage Zone). Journal of Accounting, Finance and Auditing Studies, 5(2), 106-122.

[10]. Fianu, E., Ofori, K. S., Boateng, R., \& Ampong, G. O. A. (2019, June). The Interplay Between Privacy, Trust and Self-disclosure on Social Networking Sites. In International Working Conference on Transfer and Diffusion of IT (pp. 382-401). Springer, Cham.

[11]. Hiran, K. K., \& Henten, A. (2020). An Integrated TOE-DoI Framework for Cloud Computing Adoption in Higher Education: The Case of Sub-Saharan Africa, Ethiopia. In Soft Computing: Theories and Applications (pp. 1281-1290). Springer, Singapore.

[12]. Hirschmeier, S., \& Tilly, R. (2020, January). Consumers' Need for Negative Product Information Before Reading Reviews. In Proceedings of the 53rd Hawaii International Conference on System Sciences

[13]. Jokonya, O. (2019, August). Investigating the Barriers of M-Commerce Adoption Within SMEs. In Digital innovation and transformation conference.

[14]. Kabanda, S. (2012). Power dynamics in Ecommerce adoption in least developing countries. The Case of Dar-esSalaam SMEs: Tanzania. 218-27.

[15]. Kurnia, S., Choudrie, J., Md Mahbubur, R. and Alzougool, B. (2015). E-commerce technology adoption, A Malaysian grocery SME retail sector study. Journal of Business Research, 68(9): 1906-18.

[16]. Kwateng, K. O., Atiemo, K. A. O., \& Appiah, C. (2019). Acceptance and use of mobile banking: an application of UTAUT2. Journal of Enterprise Information Management.

[17]. Lubua, E. W., \& Pretorius, P. D. (2019). Factors determining the perceived relevance of social commerce in the African context. South African Journal of Information Management, 21(1), 1-8.
[18]. Mahfouz, A. Y., Joonas, K., \& Opara, E. (2020). An overview of and factor analytic approach to flow theory in online contexts. Technology in Society, 101228.

[19]. MENSAH-ANKRAH, D. E. R. R. I. C. K. (2019). DETERMINANTS OF ADOPTION BY PROFESSIONAL FOOTBALL COACHES IN A DEVELOPING ECONOMY: EVIDENCE FROM GHANA (Doctoral dissertation, University of Ghana).

[20]. Mire, M. M. (2019). Effect of E-commerce on Performance in Agricultural Sector in Kenya: A Case of Twiga Foods Limited (Doctoral dissertation, United States International University-Africa).

[21]. Mohan, V., \& Ali, S. (2019). Challenges Faced by Indian Msmes in Adoption of Internet Marketing and E-commerce. Academy of Marketing Studies Journal.

[22]. Molitor, D., Spann, M., Ghose, A., \& Reichhart, P. (2020). Measuring the effectiveness of location-based advertising: A randomized field experiment. Available at SSRN 2645281.

[23]. Ojala, A., Rollins, M., Fraccastoro, S., \& Gabrielsson, M. (2020). The Internationalization of B2B Digital Platform Providers: The Role of Cross-National Distance and Digital Characteristics. In Proceedings of the Annual Hawaii International Conference on System Sciences. University of Hawai'i at Manoa.

[24]. Okundaye, K., Fan, S. K., \& Dwyer, R. J. (2019). Impact of information and communication technology in Nigerian small-to medium-sized enterprises. Journal of Economics, Finance and Administrative Science.

[25]. Sihotang, J., Puspokusumo, R., Sun, Y., \& Munandar, D. (2020). Core competencies of women entrepreneur in building superior online business performance in Indonesia. Management Science Letters, 10(7), 1607-1612. 
[26]. Sin, K. Y., Osman, A., Haji-Othman, Y. and Abdullah, M. S. (2015). E-commerce adoption among small and medium enterprises, SMEs in Northern state of Malaysia. Mediterranean Journal of Social Sciences, 6(5): 37-43.

[27]. Valeri, M. (2020). Blockchain Technology: Adoption Perspectives in Tourism. In

\section{Cite this article as :}

Otoo Anthony Akai Acheampong, Zhiwen Li, Antwi Maxwell. Opuni, "Estimating the Moderating Effect of Demographic Variables in B2B Ecommerce Adoption in Ghana", International Journal of Scientific Research in Science and Technology (IJSRST), Online ISSN : 2395-602X, Print ISSN : 2395-6011, Volume 7 Issue 3, pp. 38-48, May-June 2020. Available at doi : https://doi.org/10.32628/IJSRST207284

Journal URL : http://ijsrst.com/IJSRST207284
Entrepreneurship and Organizational Change (pp. 27-35). Springer, Cham.

[28]. Van Huy, L., Rowe, F., Truex, D. and Huynh, M. Q. (2012). An empirical study of determinants of E-commerce adoption in SMEs in Vietnam, An economy in transition. Journal of Global Information Management, 20(3): 2354. 